\title{
Symptoms, unmet need, and quality of life among recent breast cancer survivors
}

\author{
Steven C Palmer, PhD; Angela DeMichele, MD; Marilyn Schapira, MD, MPH; Karen \\ Glanz, PhD, MPH; Abigail N Blauch, BA; Donna A Pucci, MHK; and Linda A Jacobs, \\ $\mathrm{PhD}, \mathrm{RN}$
}

\begin{abstract}
Abramson Cancer Center of the University of Pennylvania, Philadelphia, Pennsylvania
Background Assessing patient quality of life (QoL) apart from symptoms and unmet need may miss important concerns for which remediation is possible. Therapeutic advances have improved survival among breast cancer patients, and $89 \%$ can expect to survive for longer than 5 years. However, the price is lasting physical and psychosocial symptoms. Education regarding the value of symptom reduction may be needed for breast cancer survivors and their providers.

Objective To examine the unmet needs for symptom management and the relationships between unmet needs, symptom burden, and patient QoL.

Method Eligibility included nonmetastatic breast cancer survivors who had been treated less than a year before the study and attendance at a survivorship appointment. QoL was assessed using the Medical Outcomes Study Short Form-12 (scale, 0 [Did Not Experience] to 5 [As Bad As Possible]), and 19 symptoms were evaluated. Participants reported unmet need for assistance for each symptom experienced.

Results 164 primarily white, middle-aged, early-stage survivors of breast cancer were recruited. Physical and Mental QoL were similar to national norms. Survivors reported an average of 11.5 symptoms, most commonly Fatigue, Insomnia, Hot Flashes, Joint Pain, but reported unmet need for fewer symptoms (mean, 2.6). Weight Gain, Joint Pain, Numbness were most likely to result in unmet need. Both Physical and Mental QoL were negatively associated with number of symptoms $(r=-.46$ and -.41 , respectively) and unmet needs ( $r=-.17$ and -.41 , respectively).

Limitations Cross-sectional sample of consecutive patients from a single clinical site.

Conclusion Symptoms are common among recent survivors of breast cancer, as are unmet needs, but to a lesser extent. Both have a negative impact on Physical and Mental health QoL.

Funding Translational Center of Excellence in Breast Cancer at the Abramson Cancer Center, University of Pennsylvania
\end{abstract}

There are currently more than 2.8 million breast cancer survivors in the United States ${ }^{1}$ primarily as a result of advances in early detection, surgical and chemotherapeutic procedures, focused radiation, and effective adjuvant therapeutic options, including tamoxifen and aromatase inhibitors (AIs). That number will continue to increase, and about $89 \%$ of women diagnosed with breast cancer can now expect to survive 5 years or longer. These life-saving advances have come at a cost, however, and a significant number of these women will have life-long medical and psychosocial concerns as a result of their cancer and the treatment they received. ${ }^{2-4}$ Pain, fatigue, peripheral neuropathy, distress, hormonal symptoms, and other effects of interventional therapies have been noted to be prevalent among women in the years following treatment, ${ }^{5} 6$ with previous findings suggesting that in the 5-year period after initial treatment for breast cancer more than $80 \%$ women will experience at least 1 bothersome symptom. ${ }^{7}$

The overall quality of life (QoL) of a woman with breast cancer can be influenced by numerous physical and psychosocial issues, which should be addressed by the health care team from the time of diagnosis through survivorship. However, providers often fail to recognize those issues, ${ }^{8}$ particularly if they are subjective in nature (eg, fatigue $)^{9}$ even in highly controlled clinical trials. ${ }^{10}$ Thus, patient reports remain the gold standard, ${ }^{11,12}$ and unless they are elicited by direct inquiry, they may go unreported by survivors ${ }^{9}$ leading to unmet psychosocial and physical needs. Such unmet needs appear to be common among cancer patients. Houts and colleagues, ${ }^{13}$ in the mid-1980s, found that $51 \%$ of cancer patients reported at least 1 unmet need in the year following active treatment, and a more recent replication of this research suggests that this problem has not

Accepted for publication January 8, 2016. Correspondence: Linda A Jacobs, PhD, RN; linda.jacobs@uphs.upenn.edu. Disclosures: The authors have no disclosures or conflicts of interest. JCSO 2016;14:299-306. (2016 Frontline Medical Communications. doi: 10.12788/jcso.0236. 
diminished. ${ }^{14}$ Among breast cancer survivors, specifically, research has suggested that up to $51 \%$ of women report at least 1 unmet need in the first 5 years following treatment. ${ }^{7}$ When these issues are not adequately addressed by providers, they can have an impact not only on the psychosocial and physical functioning of cancer survivors, but on adherence to follow-up recommendations, such as aromatase inhibitor (AI) use. ${ }^{15}$

Which symptoms are most likely to result in unmet need following treatment, however, is less clear, and the presence of symptoms may not indicate a desire for assistance. For example, Osse and colleagues ${ }^{16}$ found that although Dutch cancer patients reported an average of 37 symptoms and concerns during treatment, they desired additional assistance with only 8 . Similarly, Cheng and colleagues ${ }^{7}$ found that although $88 \%$ of Singaporean breast cancer patients reported at least one bothersome symptom in the 5 years following treatment, just 51\% reported at least one unmet need. It seems that physical and psychosocial symptoms vary over the disease trajectory, and that unmet need is greatest in the year following treatment and decreases over time unless there is a recurrence. ${ }^{17}$ Thus, early supportive care may be essential to maintaining or improving QoL. Unfortunately, the issue of "don't ask, don't tell" and a focus on cancer surveillance and recurrence avoidance may prevent many patients from receiving the assistance they desire for their symptom distress during clinical encounters. Patient-reported outcome (PRO) assessment may be one means of addressing this problem as even highly compromised patients have the ability to respond to selfreport questionnaires concerning their current symptom experiences. ${ }^{18}$

This study emerged from a clinical initiative to improve patient care at end of treatment and is an initial step in examining a means of improving patient assessment and, ultimately, patient outcomes. The purpose of the present study was to examine the symptoms and concerns of recently treated breast cancer patients, level and type of unmet need, demographic and treatment variables associated with concerns and unmet need, and the relationship of symptoms and unmet need to the QoL achieved by patients.

\section{Method and materials Participants}

Participants were consecutive female patients at a single facility who had completed initial or primary therapy for breast cancer within the previous 12 months. Eligibility included age of at least 18 years, confirmed diagnosis of ductal carcinoma in situ (DCIS) or nonmetastatic breast cancer, scheduled for a follow-up survivorship visit, and the ability to read, write, and understand English. Current receipt of targeted or hormonal therapy was allowed.

\section{Procedure}

Following receipt of approval by the facility's Institutional Review Board and Clinical Trials and Scientific Review Board, clinic schedules were screened for potentially eligible participants. Successive eligible participants were approached during their scheduled visit, the study explained, and informed consent obtained. Participants were then provided with a questionnaire packet to complete before meeting with their provider. Participants who were not able to complete the questionnaire before their appointment took the materials home with them and were asked to return them by mail. Up to 3 reminder calls were made if materials were not received within 2 weeks.

\section{Measures}

Demographics included age, race, ethnicity, marital status, education level, household income, and menopausal status. Disease and treatment variables were abstracted from charts and included time since diagnosis, stage at diagnosis, and treatments received.

Symptoms and unmet need were assessed using an investigator-developed questionnaire that lists 19 symptoms found to have a prevalence of $>10 \%$ in 3 separate samples of breast cancer patients and survivors $(\mathrm{N}=711)$. We use the terms symptoms and concerns interchangeably, because some represent symptoms of a given disorder whereas others represent concerns an individual may have. Concerns and symptoms included Fatigue, Pain, Insomnia, Numbness or Tingling, Aching Joints, Aching Muscles, Swelling, Depression, Difficulty Concentrating, Memory Difficulties, Anxiety, Body Image Problems, Problems with Urination, Vaginal Dryness, Decreased Sexual Interest, Hot Flashes, Night Sweats, and Weight Gain. Symptoms and concerns were presented and severity was rated on a scale of 0-5 (0, Did Not Experience; 5, As Bad As Possible). A symptom was considered present if it was rated at $\geq 1$. For each symptom scored present, participants reported whether or not they needed additional help with the symptom in a dichotomous manner. Symptoms rated as present and for which individuals desired additional assistance were considered currently unmet needs.

QoL was assessed using the Medical Outcomes Study Short Form-12. ${ }^{19}$ The SF-12 is an extensively validated instrument that has been widely used as an alternative to the more burdensome SF- $36^{20}$ and shown to account for more than $90 \%$ of the variance in SF-36 physical and mental health summary measures.

\section{Statistical analysis}

Proportions and exact confidence intervals ${ }^{21}$ are presented to describe presence of concerns or symptoms (ie, those rated as having a severity $\geq 1$ ). Associations between continuous variables are presented using Pearson correlation coefficients. Associations between continuous and categorical 
variables are presented as either point biserial correlations, t-tests, or analysis of variance (ANOVA) as appropriate.

\section{Results}

\section{Participant characteristics}

Of 267 eligible patients, 226 were approached for recruitment and $164(76.6 \%)$ were ultimately recruited and provided adequate data for analysis. Primary reasons for nonparticipation were inability to approach because the patient failed to show for an appointment $(n=21)$ and refusal to consent $(n=21)$. Most of the participants were white (72\%), middle-aged (mean, 54.5 years), married or in a marriage-like situation (65\%), employed (61.6\%) with at least a college education (64.6\%) and an annual household income of greater than $\$ 60,000$ (56.5\%; Table 1). Overall, participants reported physical QoL similar to but below normative values of 50 (mean, 48.0 [SD, 8.2]; $P<.001$ ) and mental health QoL above national norms (mean, 53.6 [SD, 11.3]; $P<.001$; both $\mathrm{t} \geq 2.96$ ). On average, women were 10.8 months from diagnosis and 5.2 months from end of acute treatment. The majority of women were diagnosed with stage 0 or I breast cancer $(57.5 \%)$, and had received surgery $(99 \%)$, chemotherapy $(60.4 \%)$, radiotherapy (65.4\%), and/or endocrine therapy (77.5\%).

\section{Presence and severity of symptoms}

On average, participants reported 11.5 (SD, 4.44) symptoms (range, 0-19; Table 2). The most commonly reported symptoms included fatigue (90\%), insomnia (75\%), hot flashes (73\%), and aching joints (70\%). ANOVA demonstrated that number of symptoms reported was positively associated with stage at diagnosis $\left(\mathrm{F}_{3,156}=5.29, P=.002\right)$ with individuals with stage III breast cancer reporting almost twice as many symptoms as those with DCIS (mean, 14.38 vs 7.36 , respectively). Similarly, those who received chemotherapy reported significantly more symptoms than chemonaïve women $\left(\mathrm{F}_{1,148}=4.15, P<.05\right)$. Number of symptoms was inversely but weakly related to time since end of treatment $(\mathrm{r}=-.17, P=.04)$ and not significantly related to age, receipt of radiation therapy, ovarian failure following treatment or receipt of AIs (all $P \geq .09$ ).

The most bothersome symptoms differed slightly from the most common symptoms, and symptom severity (scale of 0-5: 0, Did Not Experience; 5, As Bad As Possible) was highest for aching joints (mean, 2.94), decreased sexual interest (mean, 2.83), hot flashes (mean, 2.82), and vaginal dryness (mean, 2.76). Average severity for these 4 most bothersome symptoms was positively related to staging at diagnosis, and receipt of AIs (all $P<.05$ ), and marginally related to receipt of radiation therapy $(P=.053)$. Severity for the 4 most bothersome symptoms was unassociated with age, time since diagnosis or treatment, or receipt of chemotherapy (all $P>.12$ ).

Average severity across all symptoms was positively
TABLE 1 Participant demographics

\begin{tabular}{|c|c|}
\hline Characteristic & $\begin{array}{c}\text { No. of } \\
\text { respondents (\%) } \\
(\mathbf{N}=164)\end{array}$ \\
\hline Median age, 55.45 y $(S D, 11.97)$ & - \\
\hline $\begin{array}{l}\text { Median time since diagnosis, } \\
10.79 \mathrm{mo} \text {. (SD, 4.28) }\end{array}$ & - \\
\hline $\begin{array}{l}\text { Median time since end of } \\
\text { treatment, } 5.17 \mathrm{mo} \text {. (SD, 3.35) }\end{array}$ & - \\
\hline \multicolumn{2}{|l|}{ Stage at diagnosis } \\
\hline 0 & $7(4.4)$ \\
\hline I & $85(53.1)$ \\
\hline$\|$ & $55(34.4)$ \\
\hline III & $13(8.1)$ \\
\hline \multicolumn{2}{|l|}{ Treatment/therapy } \\
\hline Surgery & $163(99.3)$ \\
\hline Chemotherapy & $99(60.4)$ \\
\hline Radiotherapy & $106(65.4)$ \\
\hline Tamoxifen & $52(32.3)$ \\
\hline Aromatase inhibitor & $75(45.7)$ \\
\hline Second cancer/recurrence & $16(9.9)$ \\
\hline \multicolumn{2}{|l|}{ Race } \\
\hline White & $118(72)$ \\
\hline Black & $33(20)$ \\
\hline \multicolumn{2}{|l|}{ Marital status } \\
\hline Married/married-like & $106(64.6)$ \\
\hline Single/never married & $21(12.8)$ \\
\hline \multicolumn{2}{|l|}{ Employment status } \\
\hline Working fulltime & $82(50)$ \\
\hline Working part-time & $19(11.6)$ \\
\hline Retired & $29(17.7)$ \\
\hline Other & $34(20.7)$ \\
\hline \multicolumn{2}{|l|}{ Education } \\
\hline High school or less & 49 (29.9) \\
\hline Completed college/trade & $67(40.9)$ \\
\hline Graduate degree & $48(29.3)$ \\
\hline \multicolumn{2}{|l|}{ Annual income, US\$ } \\
\hline$<10,000-40,000$ & 30 (19) \\
\hline$>40,000-60,000$ & $16(10.1)$ \\
\hline$>60,000-100,000$ & $29(18.3)$ \\
\hline$>100,000$ & 62 (39.2) \\
\hline Declined to respond & $21(13.3)$ \\
\hline \multicolumn{2}{|l|}{ Menopausal status } \\
\hline Menopausal pre-cancer & $80(50)$ \\
\hline Menopausal post-cancer & $25(15.6)$ \\
\hline Pre/perimenopausal & 24 (15) \\
\hline Other/unsure & $31(19.4)$ \\
\hline
\end{tabular}


TABLE 2 Participant concerns, severity, and desire for intervention ( $N=164)$

\begin{tabular}{|c|c|c|c|c|}
\hline Concern & $\begin{array}{c}\% \text { of respondents } \\
\text { experiencing } \\
(95 \% \mathrm{Cl})\end{array}$ & $\begin{array}{c}\text { Severity } \\
\text { among respondents } \\
\text { experiencing, } \\
\text { mean score (SD) }\end{array}$ & $\begin{array}{l}\text { Total } \% \text { of respondents } \\
\text { wanting intervention }\end{array}$ & $\begin{array}{l}\% \text { of respondents } \\
\text { wanting intervention } \\
\text { among those } \\
\text { experiencing }\end{array}$ \\
\hline Pain & $66(60-75)$ & $2.38(1.25)$ & 14 & 32 \\
\hline Aching joints & $70(63-77)$ & $2.94(1.21)$ & 24 & 45 \\
\hline Aching muscles & $60(53-68)$ & $2.53(1.23)$ & 18 & 41 \\
\hline Swelling in limbs & $26(20-33)$ & $2.09(1.07)$ & 8 & 39 \\
\hline $\begin{array}{l}\text { Difficulty remembering } \\
\text { things }\end{array}$ & $68(60-75)$ & $2.35(1.30)$ & 13 & 26 \\
\hline Anxiety & $65(57-71)$ & $2.37(1.66)$ & 10 & 22 \\
\hline Body image problems & $60(53-68)$ & $2.31(1.34)$ & 10 & 22 \\
\hline Problems with urination & $36(29-44)$ & $2.22(1.32)$ & 12 & 43 \\
\hline Vaginal dryness & $46(39-55)$ & $2.76(1.44)$ & 12 & 37 \\
\hline Decreased sexual interest & $54(49-64)$ & $2.83(1.47)$ & 10 & 27 \\
\hline
\end{tabular}

aRated on a scale of 0-5 (0, Did Not Experience; 5, As Bad as Possible). A symptom was considered present if it was rated at $\geq 1$.

related to staging at diagnosis and receipt of chemotherapy using ANOVA (all F $>5.50$, all $P<.02$ ), but weakly and negatively related to age $(\mathrm{r}=-.19, P<.05)$. Average severity was unrelated to time since diagnosis or end of treatment, menopausal status, receipt of radiation therapy, or use of AIs $($ all $P>.20)$.

\section{Unmet need}

We examined unmet need for assistance with symptoms from two basic perspectives, the proportion of the overall sample expressing an unmet need, and the proportion of patients experiencing a symptom who reported unmet need. The former represents the level of unmet need within the clinic and is influenced by the prevalence of each symptom within the sample, while the latter allowed us to deter- mine which symptoms resulted in the most desire for assistance.

Across the sample, participants reported an average of 2.6 (SD, 3.90) unmet needs (range, 0-15). The distribution of unmet needs was positively skewed (Table 3), with $49 \%$ of the sample reporting no unmet need and 25\% reporting 4 or more unmet needs. Overall, the sample most common unmet needs were aching joints (24\%), fatigue (23\%), insomnia (20\%), and weight gain (19\%). Symptom severity by unmet need status among individuals experiencing a given concern is shown in Table 4. As can be seen, in all cases except that of weight gain, those women who wanted additional assistance rated severity significantly higher than those who did not want assistance.

The number of unmet needs was unrelated to staging at 
TABLE 3 Distribution of severity scores as a function of unmet need

\begin{tabular}{|c|c|c|c|c|c|c|}
\hline \multirow[b]{2}{*}{ Concern } & \multirow[b]{2}{*}{ Help wanted } & \multicolumn{5}{|c|}{ Severity ${ }^{a}$} \\
\hline & & 1 & 2 & 3 & 4 & 5 \\
\hline Fatigue & $\begin{array}{l}\text { Yes } \\
\text { No }\end{array}$ & $\begin{array}{c}1 \\
22\end{array}$ & $\begin{array}{c}8 \\
23\end{array}$ & $\begin{array}{l}12 \\
21\end{array}$ & $\begin{array}{l}14 \\
12\end{array}$ & $\begin{array}{l}4 \\
2\end{array}$ \\
\hline Pain & $\begin{array}{l}\text { Yes } \\
\text { No }\end{array}$ & $\begin{array}{c}5 \\
20\end{array}$ & $\begin{array}{c}5 \\
15\end{array}$ & $\begin{array}{l}5 \\
9\end{array}$ & $\begin{array}{l}4 \\
5\end{array}$ & $\begin{array}{l}4 \\
1\end{array}$ \\
\hline Insomnia & $\begin{array}{l}\text { Yes } \\
\text { No }\end{array}$ & $\begin{array}{c}5 \\
20\end{array}$ & $\begin{array}{c}5 \\
15\end{array}$ & $\begin{array}{l}5 \\
9\end{array}$ & $\begin{array}{l}4 \\
5\end{array}$ & $\begin{array}{l}4 \\
1\end{array}$ \\
\hline $\begin{array}{l}\text { Numbness or tingling } \\
\text { in limbs }\end{array}$ & $\begin{array}{l}\text { Yes } \\
\text { No }\end{array}$ & $\begin{array}{c}3 \\
13\end{array}$ & $\begin{array}{c}6 \\
10\end{array}$ & $\begin{array}{l}6 \\
5\end{array}$ & $\begin{array}{l}7 \\
3\end{array}$ & $\begin{array}{l}4 \\
2\end{array}$ \\
\hline Aching joints & $\begin{array}{l}\text { Yes } \\
\text { No }\end{array}$ & $\begin{array}{c}0 \\
14\end{array}$ & $\begin{array}{c}1 \\
10\end{array}$ & $\begin{array}{l}14 \\
16\end{array}$ & $\begin{array}{c}16 \\
7\end{array}$ & $\begin{array}{l}8 \\
0\end{array}$ \\
\hline Aching muscles & $\begin{array}{l}\text { Yes } \\
\text { No }\end{array}$ & $\begin{array}{c}0 \\
22\end{array}$ & $\begin{array}{l}6 \\
7\end{array}$ & $\begin{array}{c}8 \\
11\end{array}$ & $\begin{array}{c}10 \\
3\end{array}$ & $\begin{array}{l}6 \\
0\end{array}$ \\
\hline Swelling in limbs & $\begin{array}{l}\text { Yes } \\
\text { No }\end{array}$ & $\begin{array}{l}4 \\
8\end{array}$ & $\begin{array}{l}0 \\
6\end{array}$ & $\begin{array}{l}5 \\
4\end{array}$ & $\begin{array}{l}4 \\
1\end{array}$ & $\begin{array}{l}0 \\
0\end{array}$ \\
\hline Depression & $\begin{array}{l}\text { Yes } \\
\text { No }\end{array}$ & $\begin{array}{c}1 \\
24\end{array}$ & $\begin{array}{c}3 \\
10\end{array}$ & $\begin{array}{c}3 \\
11\end{array}$ & $\begin{array}{l}4 \\
4\end{array}$ & $\begin{array}{l}5 \\
2\end{array}$ \\
\hline $\begin{array}{l}\text { Problems with } \\
\text { concentration }\end{array}$ & $\begin{array}{l}\text { Yes } \\
\text { No }\end{array}$ & $\begin{array}{c}0 \\
19\end{array}$ & $\begin{array}{c}3 \\
13\end{array}$ & $\begin{array}{c}5 \\
10\end{array}$ & $\begin{array}{l}7 \\
8\end{array}$ & $\begin{array}{l}3 \\
0\end{array}$ \\
\hline $\begin{array}{l}\text { Difficulty remembering } \\
\text { things }\end{array}$ & $\begin{array}{l}\text { Yes } \\
\text { No }\end{array}$ & $\begin{array}{c}1 \\
30\end{array}$ & $\begin{array}{l}2 \\
8\end{array}$ & $\begin{array}{c}8 \\
12\end{array}$ & $\begin{array}{c}8 \\
10\end{array}$ & $\begin{array}{l}3 \\
2\end{array}$ \\
\hline Anxiety & $\begin{array}{l}\text { Yes } \\
\text { No }\end{array}$ & $\begin{array}{c}0 \\
25\end{array}$ & $\begin{array}{c}3 \\
12\end{array}$ & $\begin{array}{c}8 \\
15\end{array}$ & $\begin{array}{l}4 \\
5\end{array}$ & $\begin{array}{l}2 \\
1\end{array}$ \\
\hline Body image problems & $\begin{array}{l}\text { Yes } \\
\text { No }\end{array}$ & $\begin{array}{c}1 \\
28\end{array}$ & $\begin{array}{c}1 \\
14\end{array}$ & $\begin{array}{c}6 \\
10\end{array}$ & $\begin{array}{l}5 \\
3\end{array}$ & $\begin{array}{l}4 \\
4\end{array}$ \\
\hline $\begin{array}{l}\text { Problems with } \\
\text { urination }\end{array}$ & $\begin{array}{l}\text { Yes } \\
\text { No }\end{array}$ & $\begin{array}{c}4 \\
16\end{array}$ & $\begin{array}{l}4 \\
5\end{array}$ & $\begin{array}{l}5 \\
2\end{array}$ & $\begin{array}{l}2 \\
2\end{array}$ & $\begin{array}{l}4 \\
0\end{array}$ \\
\hline Vaginal dryness & $\begin{array}{l}\text { Yes } \\
\text { No }\end{array}$ & $\begin{array}{c}2 \\
14\end{array}$ & $\begin{array}{l}2 \\
5\end{array}$ & $\begin{array}{l}3 \\
7\end{array}$ & $\begin{array}{l}4 \\
5\end{array}$ & $\begin{array}{l}8 \\
2\end{array}$ \\
\hline $\begin{array}{l}\text { Decreased sexual } \\
\text { interest }\end{array}$ & $\begin{array}{l}\text { Yes } \\
\text { No }\end{array}$ & $\begin{array}{c}2 \\
15\end{array}$ & $\begin{array}{l}2 \\
6\end{array}$ & $\begin{array}{l}2 \\
8\end{array}$ & $\begin{array}{l}3 \\
9\end{array}$ & $\begin{array}{l}7 \\
5\end{array}$ \\
\hline Pain during sex & $\begin{array}{l}\text { Yes } \\
\text { No }\end{array}$ & $\begin{array}{c}0 \\
14\end{array}$ & $\begin{array}{l}0 \\
4\end{array}$ & $\begin{array}{l}3 \\
4\end{array}$ & $\begin{array}{l}3 \\
2\end{array}$ & $\begin{array}{l}4 \\
1\end{array}$ \\
\hline Hot flashes & $\begin{array}{l}\text { Yes } \\
\text { No }\end{array}$ & $\begin{array}{c}2 \\
16\end{array}$ & $\begin{array}{c}1 \\
15\end{array}$ & $\begin{array}{c}4 \\
18\end{array}$ & $\begin{array}{l}3 \\
8\end{array}$ & $\begin{array}{c}12 \\
5\end{array}$ \\
\hline Night sweats & $\begin{array}{l}\text { Yes } \\
\text { No }\end{array}$ & $\begin{array}{c}3 \\
21\end{array}$ & $\begin{array}{c}3 \\
12\end{array}$ & $\begin{array}{c}4 \\
10\end{array}$ & $\begin{array}{l}2 \\
7\end{array}$ & $\begin{array}{l}8 \\
4\end{array}$ \\
\hline Weight gain & $\begin{array}{l}\text { Yes } \\
\text { No }\end{array}$ & $\begin{array}{l}5 \\
9\end{array}$ & $\begin{array}{l}6 \\
8\end{array}$ & $\begin{array}{c}11 \\
8\end{array}$ & $\begin{array}{l}4 \\
4\end{array}$ & $\begin{array}{l}5 \\
2\end{array}$ \\
\hline
\end{tabular}

aRated on a scale of 0-5 (0, Did Not Experience; 5, As Bad as Possible). A symptom was considered present if it was rated at $\geq 1$.

the time of diagnosis, ovarian failure after diagnosis, age, time since diagnosis or treatment, or receipt of chemotherapy (all $P>.33$ ). Number of unmet needs was related to receipt of AIs such that women receiving AIs reported more unmet need (mean, 3.25) than did those who were not receiving AIs (mean, 2.01, $\mathrm{F}_{1,160}=4.29, P=.040$ ). We also examined which symptoms were more likely to result in unmet need. Among participants experiencing a given symptom, weight gain (50\%), aching joints (45\%), numbness in limbs (44\%), and urinary difficulties (43\%) were the most likely to result in unmet need.

Quality of life, symptoms, and unmet need

Physical QoL on the SF-12 was not associated with stage 
TABLE 4 Severity of concern by desire for intervention

\begin{tabular}{|c|c|c|c|}
\hline Concern & $\begin{array}{l}\text { Severity among } \\
\text { respondents wanting } \\
\text { intervention, } \\
\text { mean score (SD) }\end{array}$ & $\begin{array}{c}\text { Severity among } \\
\text { respondents not wanting } \\
\text { intervention, }{ }^{a} \\
\text { mean score (SD) }\end{array}$ & $t(P)$ \\
\hline Fatigue & $3.31(1.00)$ & $2.36(1.12)$ & $4.48(.000)$ \\
\hline Pain & $2.87(1.42)$ & 2.04 (1.09) & $2.74(.008$ \\
\hline Insomnia & $3.47(1.16)$ & $2.28(1.05)$ & $5.00(.000)$ \\
\hline Numbness or tingling in limbs & $3.12(1.28)$ & $2.12(1.22)$ & $3.05(.003)$ \\
\hline Aching joints & $3.80(0.80)$ & $2.34(1.07)$ & $7.02(.000)$ \\
\hline Aching muscles & $3.53(1.04)$ & $1.88(1.03)$ & $6.71(.000)$ \\
\hline Swelling in limbs & $2.69(1.25)$ & $1.89(0.94)$ & $2.07(.048$ \\
\hline Depression & $3.56(1.31)$ & $2.02(1.17)$ & $4.46(.000)$ \\
\hline Problems with concentration & $3.56(0.98)$ & $2.14(1.11)$ & $4.78(.000)$ \\
\hline Difficulty remembering things & $3.45(1.01)$ & $2.13(1.27)$ & $4.41(.000)$ \\
\hline Anxiety & $3.29(0.92)$ & $2.05(1.10)$ & $4.24(.000)$ \\
\hline Body image problems & $3.59(1.12)$ & $2.00(1.22)$ & $4.82(.000)$ \\
\hline Problems with urination & $2.89(1.45)$ & $1.60(0.96)$ & $3.57(.001)$ \\
\hline Vaginal dryness & $3.74(1.41)$ & $2.27(1.33)$ & $3.74(.000)$ \\
\hline $\begin{array}{l}\text { Decreased sexual } \\
\text { interest }\end{array}$ & $3.69(1.49)$ & $2.60(1.45)$ & $2.53(.014)$ \\
\hline Pain during sex & $4.10(0.88)$ & $1.74(1.26)$ & $5.44(.000)$ \\
\hline Hot flashes & $4.00(1.35)$ & $2.53(1.24)$ & $4.67(.000)$ \\
\hline Night sweats & $3.45(1.54)$ & $2.28(1.31)$ & $3.26(.002)$ \\
\hline Weight gain & $2.94(1.29)$ & $2.42(1.23)$ & $1.61(.112$ \\
\hline
\end{tabular}

a Severity rated on a scale of 0-5 (0, Did Not Experience; 5, As Bad as Possible). A symptom was considered present if it was rated at $\geq 1$ at diagnosis, receipt of chemotherapy or radiotherapy, or time since diagnosis (all $P>.41$ ). Physical QoL was modestly associated with time since end of treatment $(\mathrm{r}=0.18$, $P<.05)$, and with menopausal status $\left(\mathrm{F}_{2,116}=5.20, P<.005\right)$ such that women who were menopausal following treatment reported the lowest QoL. There was a trend for physical QoL to be associated with negatively receipt of AIs and $(P<.07)$. Mental health QoL on the SF-12 was not associated with stage at diagnosis, receipt of chemotherapy or radiotherapy, time since diagnosis or end of treatment, receipt of AIs, menopausal status, or age (all $\mathrm{F}<3.52$, all $P>$.46). Both physical and mental health QoL were negatively associated with number of concerns $(r=-.46, r=$ -.43 , all $P<.001$, respectively), average severity of concerns ( $\mathrm{r}=-.44, \mathrm{r}=-.58$, all $P<.001$, respectively), and number of unmet needs $(\mathrm{r}=-.17, \mathrm{r}=-.41$, all $P<.05$, respectively).

\section{Discussion}

This study demonstrates that breast cancer survivors within 1 year of the end of primary treatment report multiple symptoms as well as unmet needs for which they desire additional assistance. Half of the sample reported 12 or more symptoms, and 1 of 4 reported at least 15 . Unmet needs, however, were lower and participants wanted assistance with an average of only 2.6 concerns in the year following primary treatment, though this varied greatly.

Among individuals reporting a given symptom, intervention was most likely to be desired for weight gain, aching joints, numbness, tingling in limbs, and problems with urination. Between $40 \%-50 \%$ of those experiencing these issues desired intervention of some sort near the end of treatment. Importantly, these are primarily subjective concerns that may be overlooked in general clinical care. About 
one-fifth to one-quarter of the entire sample of breast cancer survivors reported unmet need for intervention with aching joints, fatigue, sleep disturbance, and weight management. At the population level, conservatively assuming 295,000 new cases ${ }^{1}$ of invasive and noninvasive breast cancer a year and a $90 \%$ survival rate, it could be estimated that there would be more than 53,100 breast cancer survivors annually who desire intervention for any one of those symptoms.

The degree to which patients experiencing a moderate level of severity for a given concern do not report a desire for assistance is also noteworthy (Table 2). For example, among individuals experiencing depression or anxiety at a level of 3:5 or greater, the majority $(63 \%$ and $60 \%$, respectively) did not desire intervention despite effective treatments being available ${ }^{22}$ even among breast cancer patients. ${ }^{23}$ Whether this lack of desire for assistance represents patient preferences regarding treatment, existing but potentially inadequate treatment, or a need for patient education is not apparent from these data, although it may signify a need for discussion and evaluation of symptoms during the clinical encounter. Regardless, assessment of patient-reported concerns, such as those investigated here, may be one means of improving outcomes and reducing symptom burden.

The most severe symptoms included aching joints, hot flashes, decreased sexual interest, and vaginal dryness. All of these have been previously associated with receipt of AIs. ${ }^{24,25} \mathrm{We}$ found that the severity of these symptoms was related to stage at diagnosis, becoming menopausal after diagnosis, and receiving AIs. Between 25\%-45\% of those experiencing these symptoms desire intervention. Unmet needs associated with receiving AIs, in particular, may represent an important target, as these symptoms have been shown to predict discontinuation of AI therapy ${ }^{26,27}$ and adherence to AIs predicts survival. ${ }^{28}$ This also highlights a need to explicitly inquire about AI-related symptom burden, as these symptoms are under-recognized by providers treating breast cancer survivors with AIs. ${ }^{29}$

Unmet need for symptom distress among breast cancer survivors represent a meaningful target for improving the QoL experienced by this population. The number of symptoms reported accounted for $16 \%-21 \%$ of the variance in mental and physical QoL, and severity of those concerns accounted for at least this much. Moreover, the number of unmet needs accounted for $34 \%$ of the variance in mental health QoL. Thus, reducing symptom burden and addressing unmet needs may be a means of improving QoL for the majority of breast cancer patients who will survive initial treatment. Moreover, those women receiving AIs reported a greater number of unmet needs, suggesting another opportunity to improve outcomes.

It is interesting to note that the even the less prevalent symptoms (eg, Swelling in Limbs, Problems With Urination, Pain During Sex, Weight Gain) were reported by more than one-quarter of the sample. Moreover, weight gain had the highest endorsement for desire for help among any of the symptoms experienced. This suggests that there may be a "teachable moment" for at least some breast cancer survivors with respect to health behaviors, ${ }^{30}$ which is potentially important because weight relates to a number of indices of post-cancer QoL, ${ }^{31}$ including survival, ${ }^{32}$ and there are now indications that weight loss may reduce the side-effects of AIs as well. ${ }^{33}$

Our data complement and extend those in the literature. Janz and colleagues ${ }^{5}$ found a somewhat lower prevalence of symptoms (mean, 6.8) among a sample of breast cancer survivors following treatment, but this sample was limited to stage 0-II patients and collapsed symptoms into presumed categories (eg, "systemic side effects") making specific comparisons difficult. The most prevalent individual symptoms, however, were strikingly similar to those in the current study (ie, Feeling Tired, Needing Rest, Hot Flashes, and Pain). Cheng and colleagues ${ }^{7}$ found that a similar set of symptoms (Lack of Energy, Numbness, Pain, Difficulty Sleeping, Worry) were prevalent (>29\%) among breast cancer survivors. Moreover, findings from this study were very similar in terms of proportion of individuals reporting at least 1 unmet need (51\%). The study by Cheng and colleagues ${ }^{7}$ was limited by a wide cross-sectional range of time since treatment (6 months to 5 years) and of not inquiring about desire for help with specific symptoms. Although symptoms experienced by breast cancer survivors at the end of treatment have been examined in the literature, unmet need for assistance with those symptoms is not often explored.

This study has some limitations. Our sample was relatively small, although it is larger than other studies examining similar issues..$^{34,35}$ In addition, although a sample of convenience, our participants were consecutive patients within a specified timeframe following treatment at a single facility and attending a survivorship visit, limiting generalizability. We believe that the symptoms and unmet needs for intervention likely represent what one could expect to encounter in a typical breast cancer survivorship clinical visit near end of treatment, but research using other samples (eg, registry based) would be needed to ensure this. We did not follow these participants over time, so it is not possible to ascertain if symptoms were recognized, intervention offered or accepted, and to what end. We are addressing this in ongoing research that utilizes an intervention to improve the recognition of unmet need with the use of an electronic PRO questionnaire in the patient's medical record, methods to facilitate remediation, and examination of associated outcomes.

\section{Conclusion}

Symptoms are common among recent breast cancer survivors and negatively impact QoL. Unmet needs and desire 
for help are less common, though similarly associated with impairment in QoL. The more severe symptoms seem to relate to receipt of AIs, suggesting that remediation could be important for maintaining adherence. Assessing symptom burden is important, but without assessing need for

\section{References}

1. Cancer Facts \& Figures 2015. http://www.cancer.org/acs/groups/ content/@editorial/documents/document/acspc-044552.pdf. Released 2015. Accessed July 1, 2016.

2. Kenyon M, Mayer DK, Owens AK. Late and long-term effects of breast cancer treatment and surveillance management for the general practitioner. J Obstet Gynecol Neonatal Nurs. 2014;43:382-398.

3. Matro JM, Goldstein LJ. How do I follow patients with early breast cancer after completing adjuvant therapy. Curr Treat Options Oncol. 2014;15:63-78.

4. Hill DA, Horick NK, Isaacs C, et al. Long-term risk of medical conditions associated with breast cancer treatment. Breast Cancer Res Treat. 2014;145:233-243.

5. Janz NK, Mujahid M, Chung LK, et al. Symptom experience and quality of life of women following breast cancer treatment. J Womens Health (Larchmt). 2007;16:1348-1361.

6. Fu OS, Crew KD, Jacobson JS, et al. Ethnicity and persistent symptom burden in breast cancer survivors. J Cancer Surviv. 2009;3:241-250.

7. Cheng KK, Darshini Devi R, Wong WH, Koh C. Perceived symptoms and the supportive care needs of breast cancer survivors six months to five years post-treatment period. Eur J Oncol Nurs. 2014;18:3-9.

8. Patrick DL, Ferketich SL, Frame PS, et al.National Institutes of Health state-of-the-science conference statement: symptom management in cancer: pain, depression, and fatigue, July 15-17, 2002. J Natl Cancer Inst. 2003;95:1110-1117.

9. Basch E, Iasonos A, McDonough T, et al. Patient versus clinician symptom reporting using the National Cancer Institute Common Terminology Criteria for Adverse Events: results of a questionnairebased study. Lancet Oncol. 2006;7:903-909.

10. Fromme EK, Eilers KM, Mori M, Hsieh YC, Beer TM. How accurate is clinician reporting of chemotherapy adverse effects? A comparison with patient-reported symptoms from the Quality-of-Life Questionnaire C30. J Clin Oncol. 2004;22:3485-3490.

11. Sneeuw KC, Sprangers MA, Aaronson NK. The role of health care providers and significant others in evaluating the quality of life of patients with chronic disease. J Clin Epidemiol. 2002;55:1130-1143.

12. Litwin MS, Lubeck DP, Henning JM, Carroll PR. Differences in urologist and patient assessments of health related quality of life in men with prostate cancer: results of the CaPSURE database. J Urol. Jun 1998;159:1988-1992.

13. Houts PS, Yasko JM, Kahn SB, Schelzel GW, Marconi KM. Unmet psychological, social, and economic needs of persons with cancer in Pennsylvania. Cancer. 1986;58:2355-2361.

14. Barg FK, Cronholm PF, Straton JB, et al. Unmet psychosocial needs of Pennsylvanians with cancer: 1986-2005. Cancer. 2007;110:631-639.

15. Kidwell KM, Harte SE, Hayes DF, et al. Patient-reported symptoms and discontinuation of adjuvant aromatase inhibitor therapy. Cancer 2014;120:2403-2411.

16. Osse BH, Vernooij-Dassen MJ, Schade E, Grol RP. The problems experienced by patients with cancer and their needs for palliative care. Support Care Cancer. 2005;13:722-732.

17. Akechi T, Uchida M, Nakaguchi T, et al. Difference of patient's perceived need in breast cancer patients after diagnosis. Jpn J Clin Oncol. 2015;45:75-80.

18. Basch E, Iasonos A, Barz A, et al. Long-term toxicity monitoring via assistance it may miss important areas for which remediation is wanted and could result in improved QoL. Patient and provider education regarding the potential for and value of assessing unmet need may be needed in breast cancer survivors to improve quality of life outcomes. electronic patient-reported outcomes in patients receiving chemotherapy. J Clin Oncol. 2007;25:5374-5380.

19. Ware J, Jr., Kosinski M, Keller SD. A 12-Item Short-Form Health Survey: construction of scales and preliminary tests of reliability and validity. Med Care. 1996;34:220-233.

20. Ware JE, Jr., Sherbourne CD. The MOS 36-item short-form health survey (SF-36). I. Conceptual framework and item selection. Med Care. 1992;30:473-483.

21. Newcombe RG. Two-sided confidence intervals for the single proportion: comparison of seven methods. Stat Med. 1998;17:857-872.

22. Archer J, Bower P, Gilbody S, et al. Collaborative care for depression and anxiety problems. Cochrane Database Syst Rev. 2012;10:CD006525.

23. Jassim GA, Whitford DL, Hickey A, Carter B. Psychological interventions for women with non-metastatic breast cancer. Cochrane Database Syst Rev. 2015;5:CD008729.

24. Gallicchio L, MacDonald R, Wood B, Rushovich E, Helzlsouer KJ. Menopausal-type symptoms among breast cancer patients on aromatase inhibitor therapy. Climacteric. 2012;15:339-349.

25. Park JH, Bae SH, Jung YS, Kim KS. Quality of life and symptom experience in breast cancer survivors after participating in a psychoeducational support program: a pilot study. Cancer Nurs. 2012;35:E34-41.

26. Henry NL, Clauw DJ. Thinking beyond the tumor to better understand chronic symptoms in breast cancer survivors. Breast Cancer Res Treat. 2012;133:413-416.

27. Cella D, Fallowfield LJ. Recognition and management of treatmentrelated side effects for breast cancer patients receiving adjuvant endocrine therapy. Breast Cancer Res Treat. 2008;107:167-180.

28. Hershman DL, Shao T, Kushi LH, et al. Early discontinuation and non-adherence to adjuvant hormonal therapy are associated with increased mortality in women with breast cancer. Breast Cancer Res Treat. Apr 2011;126:529-537.

29. Boonstra A, van Zadelhoff J, Timmer-Bonte A, Ottevanger PB, Beurskens $\mathrm{CH}$, van Laarhoven HW. Arthralgia during aromatase inhibitor treatment in early breast cancer patients: prevalence, impact, and recognition by healthcare providers. Cancer Nurs. 2013;36:52-59.

30. Ganz PA. Breast cancer, menopause, and long-term survivorship: critical issues for the 21st century. Am J Med. 2005;118(suppl 12B):136-141.

31. Schmitz KH, Neuhouser ML, Agurs-Collins T, et al. Impact of obesity on cancer survivorship and the potential relevance of race and ethnicity. J Natl Cancer Inst. 2013;105:1344-1354.

32. Protani M, Coory M, Martin JH. Effect of obesity on survival of women with breast cancer: systematic review and meta-analysis. Breast Cancer Res Treat. 2010;123:627-635.

33. Irwin ML, Cartmel B, Gross CP, et al. Randomized exercise trial of aromatase inhibitor-induced arthralgia in breast cancer survivors. J Clin Oncol. 2015;33:1104-1111.

34. Byar KL, Berger AM, Bakken SL, Cetak MA. Impact of adjuvant breast cancer chemotherapy on fatigue, other symptoms, and quality of life. Oncol Nurs Forum. 2006;33:E18-26.

35. Kenefick AL. Patterns of symptom distress in older women after surgical treatment for breast cancer. Oncol Nurs Forum. 2006;33:327-335. 